questionnaires for 106 respiratory outpatients (RO), 100 respiratory inpatients (RI, 38\% male) and 102 urology inpatients (UI, 67\% male) to answer 18 questions of the $\mathrm{CSO}^{1}$ on 5 point categorical scales for how important they value aspects of the consultation (very important - not at all important) \& how well that aspect was achieved (strongly agree - strongly disagree) in a teaching hospital over 10 weeks. Median (range) age was 68(26-91) years and 64 (20-90) years respectively and length of stay was 7 (1-93) and 4 (1-90) days respectively for $\mathbf{R I}$ and $\mathbf{U I}$ respectively.

Anonymised questionnaires on the tablet PC were completed in median (range) 264 (142-775) secs. Outcome score correlated with importance in for RI and UI (Pearson correlation coefficient, PCC, 0.90 and 0.81 respectively) but not for RO (PCC 0.56)

Questions were clustered into General satisfaction (3Q), Professional care (6Q), Depth of relationship (6Q) and Length of consultation (3Q) domains. Fig. 1 shows for each domain and each patient type, percentage of total possible scores and importance evaluated. Scores for all three patient categories were higher for general satisfaction and professional care than for depth of relationship and length of consultation. Depth of relationship was regarded as least important by all three patient categories.

We conclude patients value clinicians checking questions with them and being told about their treatment most and suggest doctors place more emphasis on this and on depth of relationship with patients. New technology allows preferences to be ascertained and analysed rapidly and accurately in a time constrained health service. Reference Kinnersley P et. al. (1996) A comparison of methods for measuring patient satisfaction with consultations in Primary Care, Family Practise, 13, 41-52.

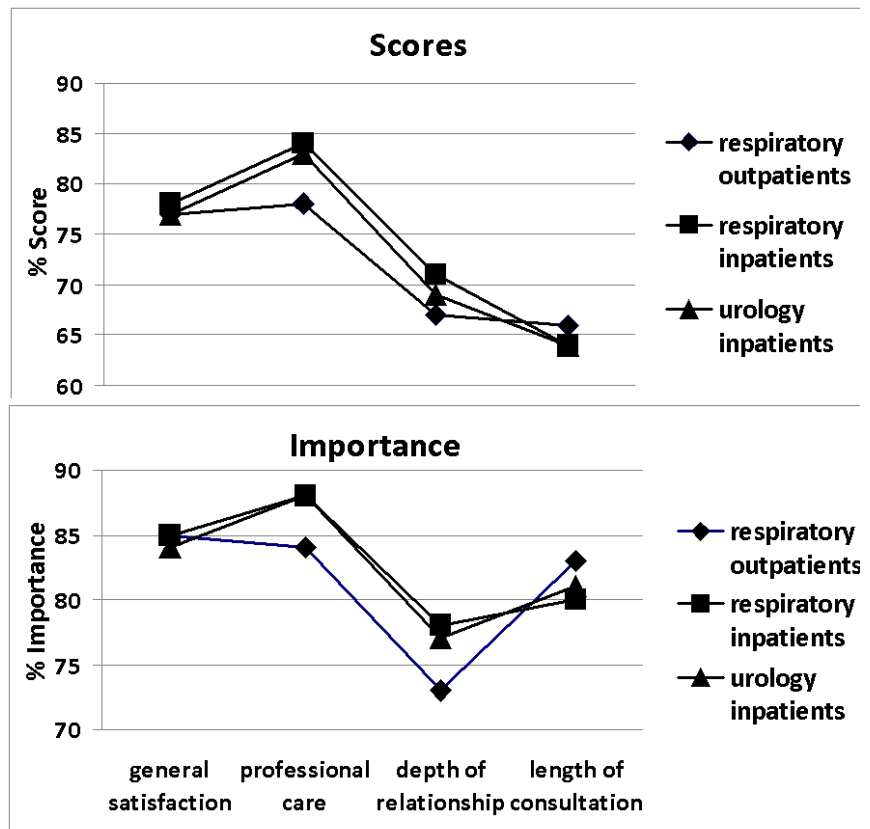

Abstract P26 Figure 1

\section{P27 \\ QUIPP ACHIEVEMENT ASSOCIATED WITH THE CREATION OF AN ACCURATE HOME OXYGEN REGISTER AND REMOVAL OF INAPPROPRIATE SHORT BURST OXYGEN THERAPY}

doi:10.1136/thoraxjnl-2012-202678.168

R Fielding, C Gelder, J Shakespeare. University Hospitals Coventry and Warwickshire, Coventry, England

Introduction The Department of Health have identified that the provision of home oxygen is an area where there are significant potentials for both quality improvements and efficiency savings. As part of a programme of work which has included renegotiation of the SHA's home oxygen supply contract, each PCT in the West Midlands has been encouraged to set up a Home Oxygen Assessment and Review service and supported to establish an accurate home oxygen register. Here we report the benefits to one PCT of establishing an accurate home oxygen register and removal of inappropriate short burst oxygen therapy.

Methods A home oxygen register was created by importing billing information into Open Exeter and uploading a list of deducted patients which were checked manually. Patients on short burst oxygen therapy were contacted and clinical need evaluated. Where appropriate these patients were reviewed by the HOS-AR team. The project commenced in July 2011 and was funded by a profit sharing agreement between the local PCT and acute Trust.

Results In 2010/11 Coventry Primary Care Trust (population $\sim 350,000$ ) spent approximately $£ 730,000$ on home oxygen therapy (excluding VAT). In July 2011 there were 966 people on the home oxygen register. Removing duplicate entries (67), deceased patients (21) and individuals who had moved to another area (16) reduced the register by 104 with an associated saving of $£ 69588$ over a nine month period. Removal of inappropriate short burst oxygen resulted in a monthly saving of approximately $£ 4,000$. Thus an annualised total saving of approximately $£ 150,000$ was achieved which equates to $20 \%$ of original spend.

Discussion This demonstrates that significant savings can be achieved rapidly simply by the creation of an accurate home oxygen register and removal of inappropriate short burst oxygen.

\section{P28 A SUCCESSFUL AMBULATORY PATHWAY FOR ELECTIVE CT GUIDED LUNG BIOPSY WHICH REDUCES BED DAYS IS CO-DEPENDANT ON ADEQUATE DISCHARGE PLANNING INCLUDING A PATHWAY FOR MANAGING PATIENTS WITH SMALL PNEUMOTHORACES}

doi:10.1136/thoraxjnl-2012-202678.169

M Tufail, T Hussain, E Hadley. Barking, Havering and Redbridge NHS Trust, Ifford, Essex, UK

Introduction and Objectives CT guided lung biopsy is a cost effective and reliable method to diagnose lung malignancy. The procedure has a low morbidity and mortality although pneumothorax complicates up to $61 \%$ of all lung biopsies. ${ }^{1}$ Patients were previously admitted for this procedure but the lack of beds and the resources prompted the conversion to an out-patient service. ${ }^{2}$ The aim of this study was to look at how a new policy for day-case CT guided biopsy of the lung affected bed-days, in particular those patients with a post biopsy pneumothorax.

Methods We collected data on CT guided lung biopsies, its complications and bed days per biopsy during 2008 when procedure was performed as inpatient and compared it with the findings when procedure was performed as day case between 2009 and 2011.

Results During 2008 we performed 35 CT guided lung biopsies as inpatients. Total bed days per biopsy were 2.31(81/35). With the introduction of a day case procedure in 2009 total bed days per biopsy were remarkably reduced to 0.12 (9/73). Post biopsy pneumothorax rate was $18.8 \%(13 / 73)$ over 3 years, but only one patient required treatment with a chest drain $7.7 \%$ (1/13). However $9 / 13$ patients were admitted for observation irrespective of the symptoms and size of the pneumothorax.

Conclusion We present evidence that the implementation of a successful day-case CT biopsy pathway has dramatically reduced bed days per successful biopsy. We have demonstrated that a further pathway for the ambulatory management of post-biopsy complications would further reduce this figure by a factor of 10 from 0.12 to 0.014 days (1/73) [see table). We recommend discharging suitably selected patients with small asymptomatic pneumothorax with an 
Abstract P28 Table 1 CT guided lung biopsies, complications and bed days per biopsy from 2008-2011

\begin{tabular}{llllll}
\hline & $\begin{array}{l}\text { Total no. of } \\
\text { procedures }\end{array}$ & $\begin{array}{l}\text { Total no. of } \\
\text { complications }\end{array}$ & $\begin{array}{l}\text { Admission rate for } \\
\text { complications }\end{array}$ & Total bed days per biopsy & $\begin{array}{l}\text { Projected bed days if ambulatory care } \\
\text { for complications implemented }\end{array}$ \\
\hline 2008 & 35 & 4 & $4 / 4(100 \%)$ & $81 / 35(2.31$ days $)$ & \\
$2009-2011$ & 73 & 13 & $9 / 13(69 \%)$ & $9 / 73(0.12$ days $)$ & $1 / 73(0.014$ days $)$ \\
\hline
\end{tabular}

appropriate information leaflet. A CXR to confirm resolution of the pneumothorax could be done when the patient returns to clinic for their biopsy results.

\section{References}

1. MacDuff A, Arnold A, Harvey J; BTS Pleural Disease Guideline Group. Management of spontaneous pneumothorax: British Thoracic Society Pleural Disease Guideline 2010 Thorax. 2010; 65.

2. CT-guided cutting needle biopsy of lung lesions-safety and efficacy of an out-patient service. Charig MJ, Phillips AJ. Clin Radiol. 2000 Dec; 55(12):964-9.

\section{P29 ACUTE RESPIRATORY ASSESSMENT SERVICE (ARAS): A NEW NURSE-LED SERVICE MANAGING PATIENTS WITH ACUTE RESPIRATORY CONDITIONS IN SECONDARY AND PRIMARY CARE}

doi:10.1136/thoraxjnl-2012-202678.170

${ }^{1} \mathrm{~A}$ Prakash, ${ }^{1} \mathrm{~S}$ Win, ${ }^{2} \mathrm{~J}$ Thompson, ${ }^{2} \mathrm{H}$ Cummings, ${ }^{2} \mathrm{~A}$ Bell, ${ }^{1} \mathrm{JA}$ Kastelik, ${ }^{1} \mathrm{JB}$ Morjaria. 'Division of Cardiovascular and Respiratory Studies, Hull York Medical School, University of Hull, Castle Hill Hospital, Cottingham, UK; ${ }^{2}$ Acute Respiratory Assessment Service, Division of Respiratory Medicine, Castle Hill Hospital, Cottingham, UK

Background Acute respiratory disorders are a huge burden to acute medical services in any healthcare system. Our institution has two large teaching hospitals providing care to a population of over 600,000 people; a mixture of inner city and rural areas.

Aim A retrospective review of outcomes of a new nurse-led specialist respiratory assessment service supported by respiratory consultants for the management of acutely unwell respiratory patients.

Methods We developed the ARAS team consisting of 3 specialist respiratory nurses supervised by 2 consultant respiratory physicians. The ARAS team reviewed all acute respiratory admissions, twice daily, to the acute medical specialist unit. They assessed inpatients on medical wards and intensive care, and provided early community discharge reviews. The ARAS team worked with community-based respiratory, oxygen, dietician and smoking cessation services.

Results Over 9 months (November 2010 to July 2011), a total of 813 patients were managed through ARAS; 446 (54.9\%) COPD, 77 (9.5\%) asthma, $111(13.7 \%)$ pneumonia, 90 (11.1\%) lower respiratory tract infection (LRTI), and 89 (10.9\%) with other respiratory conditions. More than half $(52.4 \%)$ of the patients admitted were discharged within 96 hours. There were 254 (31.2\%) patients who had supported discharges, of which 153 (60.2\%) were discharged within 96 hours. Early supported discharges ( $<96$ hours) were mainly for patients with COPD (124 (81.0\%)) and asthma (23 $(15.0 \%))$. The 30 -day readmissions were 122 (15\% of total), of which $10.2 \%$ and $<1 \%$ of all ARAS-reviewed patients had COPD and asthma, respectively.

Conclusion A dedicated specialist service provides high standard of care for patients with acute respiratory disorders and a link between the acute hospital and community services resulting in a reduced length of hospital stay with reasonably low re-admission rates in an area in the UK with high prevalence of respiratory disorders.

\section{P30 FEASIBILITY OF A NEW OUT-PATIENT BREATHLESSNESS SUPPORT SERVICE}

doi:10.1136/thoraxjnl-2012-202678.171

${ }^{1} \mathrm{CC}$ Reilly, ${ }^{1} \mathrm{C}$ Bausewein, ${ }^{2} \mathrm{C}$ Jolley, ${ }^{3} \mathrm{~J}$ Kelly, ${ }^{3} \mathrm{H}$ Bellas, ${ }^{3} \mathrm{P}$ Mandan, ${ }^{1} \mathrm{C}$ Panell, ${ }^{1} \mathrm{~S}$ De Wolf Linder, ${ }^{3} \mathrm{E}$ Brink, ${ }^{3} \mathrm{C}$ De Biase, ${ }^{2} \mathrm{~J}$ Moxham, 'I J Higginson. ' King's College London, Cicely Saunders Institute, Department of Palliative Care, Policy and Rehabilitation; 'King's College London, Department of Asthma, Allergy and Lung Biology, London, UK; '3King's College Hospital NHS Foundation Trust, London, UK

Background Breathlessness is a common and devastating symptom affecting many patients with advanced malignant and nonmalignant disease. Management comprises non-pharmacological and pharmacological interventions best delivered by a multidisciplinary group.

Aim To describe the feasibility of a study testing a newly established Breathlessness Support Service (BSS) at King's College Hospital, London.

Methods An innovative BSS with palliative care and respiratory medicine (consultant, nurse, physiotherapy, occupational therapy, and social work) input is offered since October 2010 to patients with refractory breathlessness due to advanced malignant and nonmalignant disease. Patients are seen twice in the clinic and offered a home visit by physiotherapy and occupational therapy. The new service is evaluated in a phase 3 fast track randomised controlled trial (RCT) comparing immediate or delayed (after 6 weeks) access to BSS.

Results Between October 2010 and June 2012, 191 patients have been referred to our study, of which 88 patients have consented to partake in the study (48/88 male; median age 68 y (range 40-84 y); 62/88 carer present; COPD 45, Cancer 17, ILD 18, heart failure 6, Asthma 1, other 1). Of these 88 patients, 60 patients have completed the study (primary endpoint at 6 weeks), with 11 patients awaiting their 6 week assessment. The current attrition rate for the primary endpoint of the study (6 weeks) is approximately $19 \%$, much less than $40 \%$ we originally anticipated. 40 have completed the 12 week follow up home visit (secondary endpoint), with 12 patients awaiting their 12 week assessment. The current attrition rate for the secondary end point is 34\%, reflective of the complexity of retaining palliative care patients in a RCT. The BSS is well received by patients. Main organisational problems relate to transport to the BSS and patients being unwell to attend the second clinic visit.

Conclusion Referral to the study is similar to what we expected with the number of patients consenting (46\%) to partake similar to that reported in the pulmonary rehabilitation literature. Once in the trial, attrition is low. Overall, the BSS seems to be feasible.

\section{P31 DO LUNG CANCER PATIENTS GET A BETTER DEAL IF THEY PRESENT BY TWO WEEK WAIT PATHWAY?}

doi:10.1136/thoraxjnl-2012-202678.172

E Nuttall, K Mitton, M Wilkoninson, G Jifon, A Ansari, S Bari. Royal Lancaster Infirmary, Lancaster, Lancashire

Introduction Introduction of one stop lung cancer[LC] clinics have shortened the patient journey of 2 week wait [2WW] referral 